\title{
Solving optimal reactive power problem by hurricane search optimization algorithm
}

\author{
Kanagasabai Lenin \\ Department of EEE, Prasad V. Potluri Siddhartha Institute of Technology, India
}

\begin{tabular}{l}
\hline \hline Article Info \\
\hline Article history: \\
Received Jan 3, 2020 \\
Revised Feb 19, 2020 \\
Accepted Feb 20, 2020 \\
\hline
\end{tabular}

\section{Keywords:}

Hurricane search optimization algorithm Reactive power Transmission loss

\begin{abstract}
In this paper proposed hurricane search optimization (HSO) algorithm is proposed to solve optimal reactive power problem. An upward motion of air is caused due to release of heat which creates a low-pressure zone and by the rotation of the earth that is set into spin. In this spiraling airflow when energy is high then hurricane is created. Projected HSO algorithm design is based on the examination of the horizontal wind structure in a hurricane and how the wind parcels the progression in the neighboring atmosphere. A mixture of wind models has been developed for past few years to Backtesting and to compute hurricane exterior wind fields. Proposed HSO algorithm has been tested in standard IEEE 30, 57bus test systems and simulation results show the projected algorithm reduced the real power loss considerably.
\end{abstract}

This is an open access article under the $\underline{C C B Y-S A}$ license.

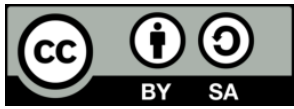

\section{Corresponding Author:}

Kanagasabai Lenin

Department of Electrical and Electronics Engineering

Prasad V. Potluri Siddhartha Institute of Technology

Kanuru, Vijayawada, Andhra Pradesh-520007, India

Email: gklenin@gmail.com

\section{INTRODUCTION}

Reactive power problem ius important for economic operations of power system. To solve the problem numerous types of methods [1-16] have been utilized. This paper proposes hurricane search optimization (HSO) algorithm to solve the problem. Over tropical and subtropical oceans with warm core hurricane is a low-pressure zone will be formed. A large amount of energy from the sun is received by the tropical and subtropical oceans. In the form of water vapor this energy is let into the environment. Towards the center, winds are primarily amplified in exponential mode, subsequently plunge quickly towards quiet. Towards the center pressure diminish exponentially and within the hurricane eye it settle down in a reasonably plane region of lowest pressure. A swirling flow can be described in parametric mode of a Rankine vortex model. Center of the flow is in solid rotation mode in the inner radial region. Whereas the outer region is liberated of vorticity and a swirling flow can be described in parametric mode of a Rankine vortex model. Center of the flow is in solid rotation mode in the inner radial region. Proposed HSO algorithm has been tested in standard IEEE 30, 57 bus test systems and simulation results show the projected algorithm reduced the real power loss considerably.

\section{PROBLEM FORMULATION}

$$
\mathrm{F}=\mathrm{P}_{\mathrm{L}}=\sum_{\mathrm{k} \in \mathrm{Nbr}} \mathrm{g}_{\mathrm{k}}\left(\mathrm{V}_{\mathrm{i}}^{2}+\mathrm{V}_{\mathrm{j}}^{2}-2 \mathrm{~V}_{\mathrm{i}} \mathrm{V}_{\mathrm{j}} \cos \theta_{\mathrm{ij}}\right)
$$


$\mathrm{F}=\mathrm{P}_{\mathrm{L}}+\omega_{\mathrm{v}} \times$ Voltage Deviation

Voltage Deviation $=\sum_{\mathrm{i}=1}^{\mathrm{Npq}}\left|\mathrm{V}_{\mathrm{i}}-1\right|$

$\mathrm{P}_{\mathrm{G}}=\mathrm{P}_{\mathrm{D}}+\mathrm{P}_{\mathrm{L}}$

$\mathrm{P}_{\text {gslack }}^{\min } \leq \mathrm{P}_{\text {gslack }} \leq \mathrm{P}_{\text {gslack }}^{\max }$

$\mathrm{Q}_{\mathrm{gi}}^{\min } \leq \mathrm{Q}_{\mathrm{gi}} \leq \mathrm{Q}_{\mathrm{gi}}^{\max }, \mathrm{i} \in \mathrm{N}_{\mathrm{g}}$

$V_{i}^{\min } \leq V_{i} \leq V_{i}^{\max }, i \in N$

$\mathrm{T}_{\mathrm{i}}^{\min } \leq \mathrm{T}_{\mathrm{i}} \leq \mathrm{T}_{\mathrm{i}}^{\max }, \mathrm{i} \in \mathrm{N}_{\mathrm{T}}$

$\mathrm{Q}_{\mathrm{c}}^{\min } \leq \mathrm{Q}_{\mathrm{c}} \leq \mathrm{Q}_{\mathrm{C}}^{\max }, \mathrm{i} \in \mathrm{N}_{\mathrm{C}}$

\section{HURRICANE SEARCH OPTIMIZATION ALGORITHM}

Over tropical and subtropical oceans with warm core hurricane is a low-pressure zone will be formed. A large amount of energy from the sun is received by the tropical and subtropical oceans. In the form of water vapor this energy is let into the environment. An upward motion of air is caused due to release of heat which creates a low-pressure zone and by the rotation of the earth that is set into spin. Towards the center, winds are primarily amplified in exponential mode, subsequently plunge quickly towards quiet. Towards the center Pressure diminish exponentially and within the hurricane eye it settle down in a reasonably plane region of lowest pressure. In hurricane Vortex created on the zenith of the horizontal surface can be approximated by using logarithmic $(\log )$ spiral pattern log spirals and it can be defined by:

$$
r(\theta)=a \cdot \exp (b \cdot \theta),\left\{\begin{array}{l}
x(\theta)=r(\theta) \cos (\theta)+e_{x} \\
y(\theta)=r(\theta) \cos (\theta)+e_{y}
\end{array}\right.
$$

A swirling flow can be described in parametric mode of a Rankine vortex model.

$$
\begin{aligned}
& V=V_{\max } \frac{r}{R_{\max }} \text { if } r<R_{\max } \\
& V=V_{\max }\left(\frac{R_{\max }}{r}\right)^{x} \text { if } r>R_{\max } \\
& X_{i}=\left(x_{i}^{1}, \ldots, x_{i}^{d}, \ldots, x_{i}^{n}\right) \text { for } \mathrm{i}=1,2,3, \ldots, \mathrm{N} \\
& x_{i}^{j}=\left\{\begin{array}{c}
r_{i}(t) \cos \left(\varphi_{\text {initial }}^{i}+\varphi_{i}(t)\right)+e_{j} \text { if } j=k \\
r_{i}(t) \sin \left(\varphi_{\text {initial }}^{i}+\varphi_{i}(t)\right)+e_{j} \text { if } j=k+1 \\
e_{j} \text { otherwise }
\end{array}\right. \\
& r_{i}(t)=R_{o} \cdot \exp \left(\text { random. } \varphi_{i}(t)\right)
\end{aligned}
$$

In the interval $[0,2 \pi] \varphi_{\text {initial }}^{i}$ for $\mathrm{i}=1,2,3, \ldots, \mathrm{N}$ are arbitrarily engendered.

$$
\left\{\begin{array}{c}
\varphi_{i}(t+1)=\varphi_{i}(t) ; \text { if } r_{i} \leq R_{\max } \\
\varphi_{i}(t+1)=\varphi_{i}(t)+\omega \cdot\left(\frac{R_{\max }}{r}\right)^{\text {random }} \text {; if } r_{i}>R_{\max }
\end{array}\right.
$$

Every time parcel $X_{i}^{k}$ alters its position, pressure then $\mathrm{P}_{\mathrm{i}}$ weighs against to the eye pressure $\mathrm{P}_{\text {eye }}$.

$$
\begin{aligned}
& P_{i}=\text { fit }_{i}(t)=f\left(x_{i}^{1}, \ldots, x_{i}^{d}, \ldots, x_{i}^{n}\right) \\
& P_{\text {eye }}=\left\{\begin{array}{c}
\arg \min _{i \in\{1, . ., N\}} \text { fit } t_{i} \text { minimization } \\
-\arg \max _{i \in\{1, . ., N\}} \text { maximization }
\end{array}\right.
\end{aligned}
$$

Commence

Solving optimal reactive power problem by hurricane search optimization algorithm (Kanagasabai Lenin) 


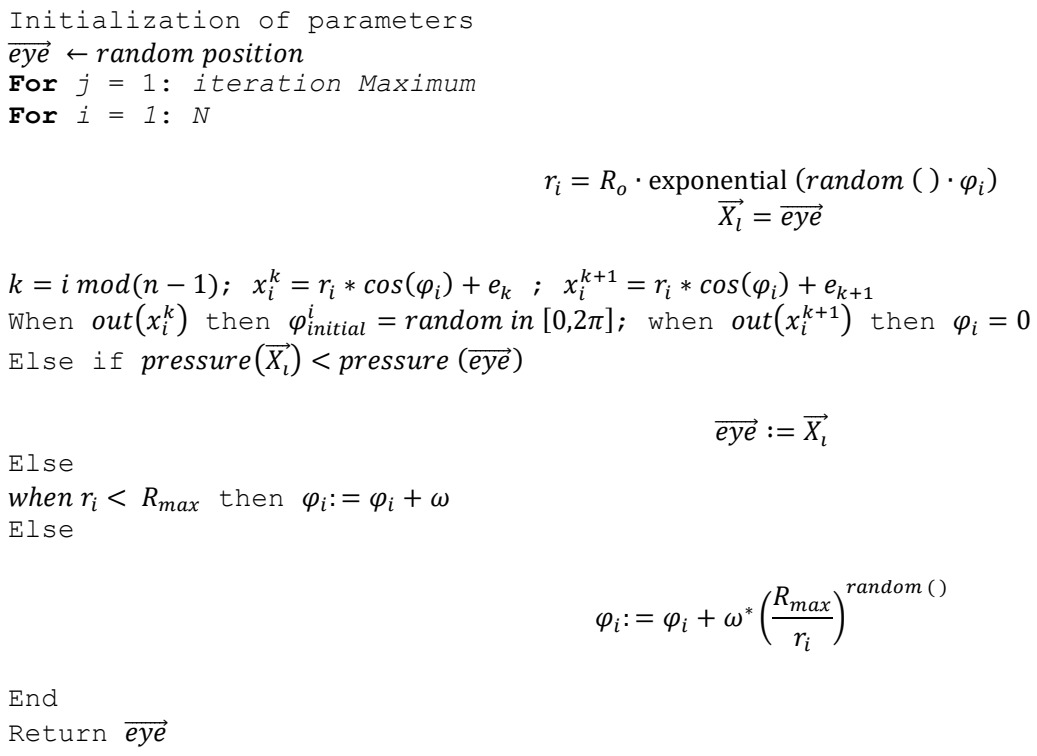

\section{SIMULATION STUDY}

HSO algorithms is tested, in IEEE 30 and 57 Bus systems [17]. Comparison results are presented in Table 1 and Table 2.

Table 1. Simulation results of IEEE-30 system

\begin{tabular}{lllllll}
\hline Control variables & Base case & MPSO [18] & PSO [18] & EP [18] & SARGA [18] & HSO \\
\hline$P G(\mathrm{MW})$ & 300.9 & 299.54 & 299.54 & $\mathrm{NR}^{*}$ & $\mathrm{NR}^{*}$ & 298.98 \\
$Q G$ (Mvar) & 133.9 & 130.83 & 130.94 & $\mathrm{NR}^{*}$ & $\mathrm{NR}^{*}$ & 130.73 \\
Reduction in PLoss (\%) & 0 & 8.4 & 7.4 & 6.6 & 8.3 & 14.90 \\
Total PLoss (Mw) & 17.55 & 16.07 & 16.25 & 16.38 & 16.09 & 14.935 \\
\hline
\end{tabular}

Table 2. Simulation results of IEEE-57 system

\begin{tabular}{lllllll}
\hline Control variables & Base case & MPSO [18] & PSO [18] & CGA [18] & AGA [18] & HSO \\
\hline Reduction in PLoss (\%) & 0 & 15.4 & 14.1 & 9.2 & 11.6 & 25.39 \\
Total PLoss (Mw) & 27.8 & 23.51 & 23.86 & 25.24 & 24.56 & 20.741 \\
\hline
\end{tabular}

\section{CONCLUSION}

In this paper HSO algorithm successfully solved the optimal reactive power problem. A mixture of wind models has been developed for past few years to Backtesting and to compute hurricane exterior wind fields. In hurricane Vortex created on the zenith of the horizontal surface can be approximated by using logarithmic $(\log )$ spiral pattern $\log$ spirals. Center of the flow is in solid rotation mode in the inner radial region. Proposed HSO algorithm has been evaluated in IEEE 30, 57 bus test systems. The simulation result show that power loss reduction is obtained.

\section{REFERENCES}

[1] K. Y. Lee, "Fuel-cost minimisation for both real and reactive-power dispatches," Proceedings Generation, Transmission and Distribution Conference, vol. 131, no. 3, pp. 85-93, 1984.

[2] N. I. Deeb, "An efficient technique for reactive power dispatch using a revised linear programming approach," Electric Power System Research, vol. 15, no. 2, pp. 121-134, 1988.

[3] M. R. Bjelogrlic, M. S. Calovic, B. S. Babic, "Application of Newton's optimal power flow in voltage/reactive power control," IEEE Trans Power System, vol. 5, no. 4, pp. 1447-1454, 1990.

[4] S. Granville, "Optimal reactive dispatch through interior point methods," IEEE Transactions on Power System, vol. 9, no. 1, pp. 136-146, 1994.

[5] N. Grudinin, "Reactive power optimization using successive quadratic programming method," IEEE Transactions on Power System, vol. 13, no. 4, pp. 1219-1225, 1998. 
[6] Wei Yan, J. Yu, D. C. Yu, K. Bhattarai. "A new optimal reactive power flow model in rectangular form and its solution by predictor corrector primal dual interior point method," IEEE Trans. Pwr. Syst, vol. 21, no. 1, pp. 61-67, 2006.

[7] S. Surender Reddy, "Optimal reactive power scheduling using cuckoo search algorithm," International Journal of Electrical and Computer Engineering, vol. 7, no. 5, pp. 2349-2356, 2017.

[8] S. Surender Reddy, P. R. Bijwe and A. R. Abhyankar, "Faster evolutionary algorithm based optimal power flow using incremental variables," Electrical Power and Energy Systems, vol. 54, pp. 198-210, 2014.

[9] Mahaletchumi Morgan, et al., "Multi-objective evolutionary programming (MOEP) using mutation based on adaptive mutation operator (AMO) applied for optimal reactive power dispatch," ARPN Journal of Engineering and Applied Sciences, vol. 11, no. 14, pp. 8884-8888, 2016

[10] Pandiarajan, K. and Babulal, C. K., "Fuzzy harmony search algorithm based optimal power flow for power system security enhancement," International Journal Electric Power Energy Syst., vol. 78, pp. 72-79, 2016.

[11] Mahaletchumi Morgan, Nor Rul Hasma Abdullah, Mohd Herwan Sulaiman, Mahfuzah Mustafa, Rosdiyana Samad, "benchmark studies on optimal reactive power dispatch (ORPD) based multi-objective evolutionary programming (MOEP) using mutation based on adaptive mutation operator (AMO) and polynomial mutation operator (PMO)," Journal of Electrical Systems, vol. 12, no. 1, pp. 121-132, 2016

[12] Rebecca Ng Shin Mei, Mohd Herwan Sulaiman, Zuriani Mustaffa, "Ant lion optimizer for optimal reactive power dispatch solution," Journal of Electrical Systems, Special Issue AMPE2015, pp. 68-74, 2016.

[13] Gagliano A., Nocera F., "Analysis of the performances of electric energy storage in residential applications," International Journal of Heat and Technology, vol. 35, no. 1, pp. S41-S48, 2017.

[14] Caldera M., Ungaro P., Cammarata G., Puglisi G., "Survey-based analysis of the electrical energy demand in Italian households, " Mathematical Modelling of Engineering Problems, vol. 5, no. 3, pp. 217-224, 2018.

[15] E. Rashedi, S. Nezamabadi, and S. Saryazdi, "GSA: A gravitational search algorithm," Information Sciences, vol. 179 , no. 13 , pp. 2232-2248, 2009.

[16] Gai-Ge Wang, "Moth search algorithm: a bio-inspired metaheuristic algorithm for global optimization problems," Memetic Comp., vol. 10, no. 2, pp. 151-164, 2016.

[17] IEEE, "The IEEE-test systems," 1993, http://www.ee.washington.edu/trsearch/pstca/.

[18] Ali Nasser Hussain, et al., "Modified particle swarm optimization for solution of reactive power dispatch," Research Journal of Applied Sciences, Engineering and Technology, vol. 15, no. 8, pp. 316-327, 2018.

\section{BIOGRAPHY OF AUTHOR}

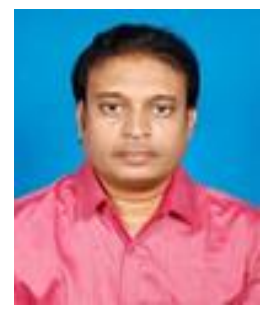

Kanagasabai Lenin has received his B.E., degree, electrical and electronics engineering from University of Madras, M.E., degree in power system from Annamalai University and completed $\mathrm{PhD}$ in electrical engineering from Jawaharlal Nehru Technological University Hyderabad, India. He published more than 275 international journal research papers and presently working as Professor in Prasad V. Potluri Siddhartha Institute of Technology, Kanuru, Vijayawada, Andhra Pradesh -520007. 